\title{
Prevalence and Characteristics of Peripartum Cardiomyopathy among Women with Cadiac Failure Referred for Echocardiography in a Tertiary Hospital in Northern Nigeria
}

\author{
Hadiza Saidu ${ }^{*}$, Abdulwahab Kabir ${ }^{1}$, Nkem Ndiche², Jamila A. Yau ${ }^{3}$, \\ Umar Abdullahi' ${ }^{4}$, M. S. Mijinyawa ${ }^{5}$ \\ ${ }^{1}$ Department of Medicine, Bayero University/Murtala Muhammad Specialist Hospital, Kano, Nigeria \\ ${ }^{2}$ Department of Family Medicine, Murtala Muhammad Specialist Hospital, Kano, Nigeria \\ ${ }^{3}$ Department of Medicine, Public Health and Diagnostic Institute, North-West University, Kano, Nigeria \\ ${ }^{4}$ Department of Medicine, Ahmad Sani Yariman Bakura Specialist Hospital, Gusau, Nigeria \\ ${ }^{5}$ Department of Medicine, Bayero University/Aminu Kano Teaching Hospital, Kano, Nigeria \\ Email: *hsaidu2006@yahoo.com
}

How to cite this paper: Saidu, H., Kabir, A., Ndiche, N., Yau, J.A., Abdullahi, U. and Mijinyawa, M.S. (2018) Prevalence and Characteristics of Peripartum Cardiomyopathy among Women with Cadiac Failure Referred for Echocardiography in a Tertiary Hospital in Northern Nigeria. Journal of Biosciences and Medicines, 6, 95-104. https://doi.org/10.4236/jbm.2018.63007

Received: February 3, 2018

Accepted: March 11, 2018

Published: March 14, 2018

Copyright $\odot 2018$ by authors and Scientific Research Publishing Inc. This work is licensed under the Creative Commons Attribution International License (CC BY 4.0).

http://creativecommons.org/licenses/by/4.0/

\begin{abstract}
Introduction: Peripartum cardiomyopathy (PPCM) is a common clinical condition in northern Nigeria. This study aimed to determine the prevalence and characteristics of PPCM among women with heart failure referred for echocardiography. Materials and Methods: This is a retrospective study of 401 women managed for heart failure referred for echocardiography between October 2016 and September 2017. Their reports were analyzed for demographic and echocardiographic parameters. Results: The mean age of the 401 individuals studied was $41.28 \pm 16.25$ years. The commonest cause of heart failure was PPCM, accounting for 256 (69.5\%), followed by hypertension 79 (19.7\%) and rheumatic heart disease (RHD) 24 (5.9\%). Conclusion: PPCM is a common and important cause of heart failure among women in Northern Nigeria.
\end{abstract}

\section{Keywords}

Peripartum Cardiomyopathy, Echocardiography, Northern Nigeria, Tertiary Hospital

\section{Introduction}

Heart failure is a chronic condition characterized by inability of the heart to 
pump adequate blood to meet the demands of the body and/or doing so at increased filling pressures. It is a serious and major clinical problem worldwide. It has been recognized as a contributor to cardiovascular disease burden in Africa, and an important cause of hospital admission [1]-[6].

Available data suggest that the etiologies of heart failure in Africa differ from those in the Western world [7]. The most common underlying cause of heart failure in high-income countries is coronary artery disease [8]. In sub-Saharan Africa, the predominant causes are hypertensive heart disease, rheumatic heart disease and cardiomyopathies [9] [10] [11].

Peripartum cardiomyopathy is defined as dilated cardiomyopathy of uncertain origin that occurs in pregnant women from the last trimester to the postpartum period with no preexisting heart disease [12]. It is recognized as a separate entity because of its distinct epidemiologic characteristics, relatively rapid onset and association with unique auto antigens and autoantibodies [13].

Virchow recognized heart failure in association with pregnancy as early as 1880 [14]. However, it was not until the 1930s when Hull and Hafkes formally described the syndrome of heart failure following pregnancy as "postpartum cardiomyopathy" [14]. Demakis and Rahmitoola in 1971 formally defined PPCM and gave criteria for its diagnosis, the basis of which remains today [15].

Although several studies have assessed the clinical profile and natural history of the condition, there is still the need of data from parts of the world with high disease prevalence. With the availability of echocardiographic facility in our centre, we observed a change in trend in the aetiology and pattern of presentation of heart failure among women. The prevalence of PPCM was noted to be rising. The present study aims to determine the prevalence and characteristics of PPCM among women with heart failure referred for echocardiography.

\section{Methods}

This is a retrospective study of the echocardiographic data of women with heart failure referred for echocardiography collected over 1 year period between $1^{\text {st }}$ October 2016 to $30^{\text {th }}$ September 2017. The study was carried out at Murtala Muhammad Specialist Hospital (MMSH), Kano. Subjects were eligible if they were 18 years and older and with a confirmed diagnosis of heart failure. Heart failure was defined according to the recommendations of the European Society of Cardiology [16]. The New York Heart Association functional (NYHA) of the subjects was also assessed [17].

Baseline clinical and demographic characteristics were obtained from the patient's folders and echocardiography register. These included: age, place of residence, parity, BMI (body mass index), BP (blood pressure) at time of first presentation, echocardiographic parameters and diagnoses.

Ethical approval was obtained from the institution's ethical review committee.

\section{Procedure}

M-mode and two-dimensional echocardiography, with colour Doppler imaging 
were performed on all the patients by three cardiologists, using Toshiba HDI Machine and a 2.5 to $5.0 \mathrm{~Hz}$ linear array transducer, according to the recommendation of the American Society of Echocardiography (ASE) [18]. Subjects were examined in the left lateral decubitus position using standard parasternal, short axis and apical views. The M-mode cursor on the $2 \mathrm{D}$ scan was moved to specific areas of the heart to obtain measurements according to the recommendations of the committee on M-mode standardization of the ASE [19]. From the M-mode measurements, indices of Left Ventricular (LV) function were derived. Left ventricular systolic function was calculated by Teicholz formula, and LV systolic dysfunction was defined as left ventricular ejection fraction (LVEF) < $50 \%[20]$.

Left ventricular diastolic dysfunction was defined and graded using transmitral inflow velocities as: Normal diastolic filling pattern (values of $\mathrm{E} / \mathrm{A}=1-1.5$; $\mathrm{DT}=160-240 \mathrm{~ms} ;$ IVRT $=70-90 \mathrm{~ms}$ ), Grade I diastolic dysfunction (reduced E/A < 1.0; prolonged DT > $240 \mathrm{~ms}$; and prolonged IVRT $>90 \mathrm{~ms}$ ), Grade II diastolic dysfunction (E/A 1 - 1.5; DT $160-240$ and IVRT $<90 \mathrm{~ms}$ ), Grade III diastolic dysfunction (increased E/A $>1.5$; reduced DT $<160 \mathrm{~ms}$ and IVRT $<70$ $\mathrm{ms}) .(\mathrm{E}=$ early rapid filling wave; A wave = filing wave due to atrial contraction; $\mathrm{DT}=$ deceleration time; IVRT $=$ isovolumic relaxation time) [21].

Peripartum Cardiomyopathy was diagnosed based on the temporal relation of heart failure to last pregnancy and delivery as proposed in the European Society of Cardiology (ESC) working group on PPCM guidelines, if these four criteria are met: [22]

1) Development of cardiac failure in the last month of pregnancy or within 5 month of delivery.

2) Absence of an identifiable cause of cardiac failure.

3) Absence of recognizable heart disease prior to the last month of pregnancy and

4) Echocardiographic finding of left ventricular systolic dysfunction (depressed shortening fraction or ejection fraction).

Hypertensive Heart Disease (HHD), Rheumatic heart disease, Dilated Cardiomyopathy (DCM), Corpulmonale and Ischemic heart disease (IHD) were diagnosed according to standard criteria [23] [24] [25] [26] [27].

Data analyses were performed with SPSS software (version 18, Inc, Chicago, IL, USA). Continuous variables were expressed as mean \pm SD (Standard deviation) and categorical variables expressed as percentages.

\section{Results}

Four hundred and ninety-eight women were referred for echocardiography during the study period out of which 401 (80.5\%) had diagnosis of heart failure. The mean age of the subjects was $41.28 \pm 16.25$ years. The commonest cause of heart failure was PPCM accounting for 256 (69.5\%), followed by hypertension 79 (19.7\%) and RHD 24 (5.9\%). One hundred and one subjects were in-patients 
while 155 (61.4\%) were out-patients attended to at the Cardiology out-patient and Family medicine clinics. Records of 182 (71.1\%) patients with complete data were analyzed. The age of the patients with PPCM ranged from 17 to 45 years, with a mean of $27.8 \pm 8.1$. One hundred and two patients (56.5\%) had only informal education. Of the 80 (43.5\%) with formal education, 36 (19.7\%) had primary education, $42(23.2 \%)$ had secondary education while only $2(1.1 \%)$ had tertiary education. One hundred and sixty-nine patients (92.8\%) are married while 13 (7.2\%) are divorced. Eighty (44\%) of the patients are primipara (1 delivery), while $36(20 \%)$ are multipara ( 2 - 5 deliveries) and $66(36 \%)$ are grand multipara ( $>5$ deliveries). Table 1 shows the socio-demographic characteristics of the study population. Figure 1 shows the causes of heart failure among females.

The mean left ventricular end diastolic dimension (LVEDD) was $59.4 \pm 7.8$. Sixty-eight percent 124 (68\%) of the patients had severe left ventricular systolic dysfunction $(\mathrm{EF}<35 \%)$. Thrombus in the Left ventricle was found in $10(5.4 \%)$ and 3 (33.3\%) had stroke. LV diastolic dysfunction was found in (157) $86.5 \%$. Figure 2 shows the pattern of LV dysfunction among the PPCM patients. Table 2 shows the echocardiographic characteristics of patients with PPCM.

Table 1. Socio-demographic characteristics of the patients with PPCM.

\begin{tabular}{|c|c|c|}
\hline Characteristic & Mean & Standard deviation \\
\hline Age (years) & 27.8 & 12.3 \\
\hline BMI $\left(\mathrm{Kg} / \mathrm{m}^{2}\right)$ & 21.5 & 4.2 \\
\hline SBP (mmHg) & 112.6 & 18.7 \\
\hline $\mathrm{DBP}(\mathrm{mmHg})$ & 81.3 & 17.2 \\
\hline \multirow[t]{2}{*}{ Parity } & 4 & 3 \\
\hline & Frequency (n) & Percentage (\%) \\
\hline \multicolumn{3}{|l|}{ Tribe } \\
\hline Hausa - Fulani & 180 & 98.9 \\
\hline Yoruba & 2 & 1.1 \\
\hline \multicolumn{3}{|l|}{ Parity } \\
\hline Primiparous & 80 & 44 \\
\hline Multiparous & 102 & 56 \\
\hline \multicolumn{3}{|l|}{ NYHA class } \\
\hline Class I & 52 & 28.2 \\
\hline Class II & 72 & 39.8 \\
\hline Class III & 45 & 24.6 \\
\hline Class IV & 13 & 7.4 \\
\hline Consumption of dried lake salt & 67 & 37 \\
\hline Hot water bath & 84 & 46.2 \\
\hline
\end{tabular}

Key: BMI, body mass index; SBP, systolic blood pressure; DBP, diastolic blood pressure; NYHA, New York Heart Association. 


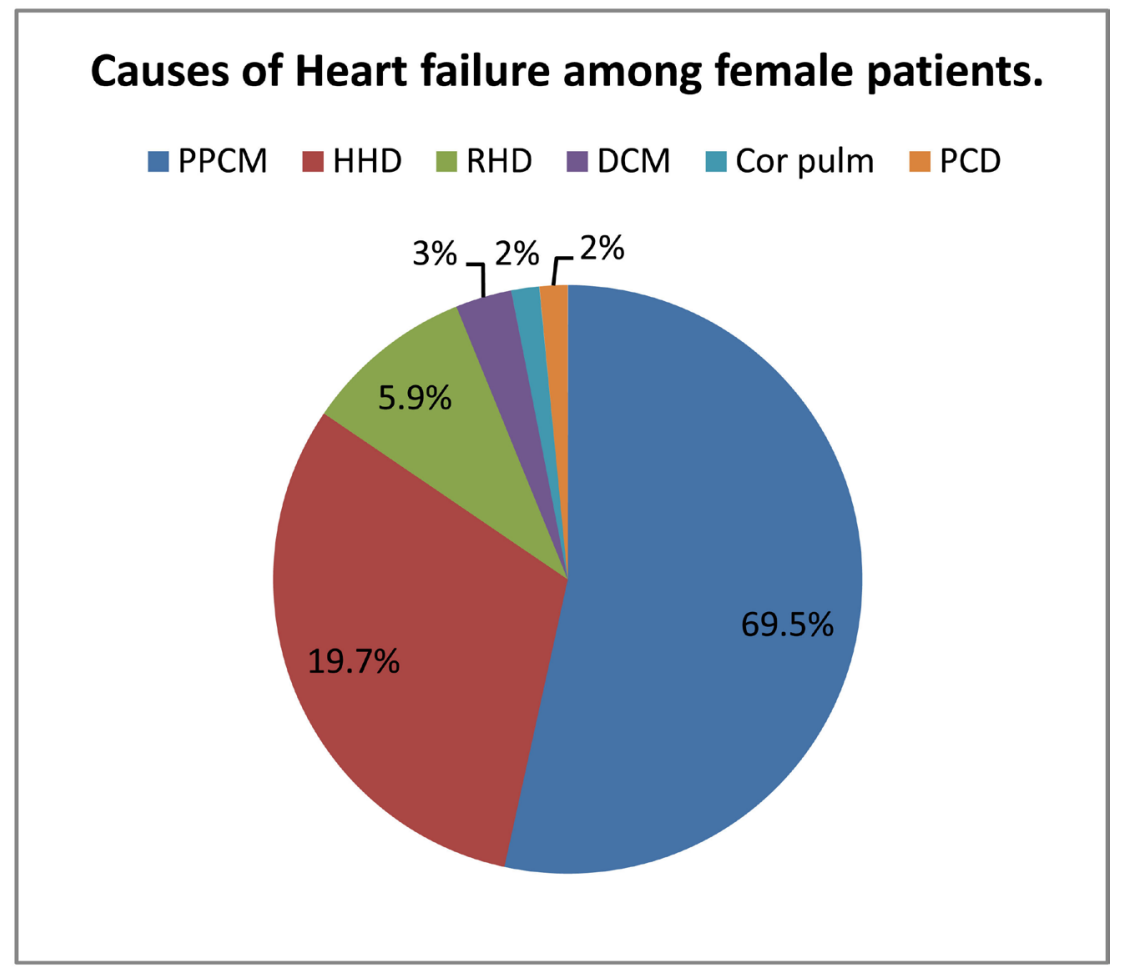

Key: PPCM, Peripartum cardiomyopathy; HHD, Hypertensive heart disease; RHD, Rheumatic heart disease; DCM, Dilated cardiomyopathy, PCD, Pericardial diseases.

Figure 1. Causes of heart failure among female patients.

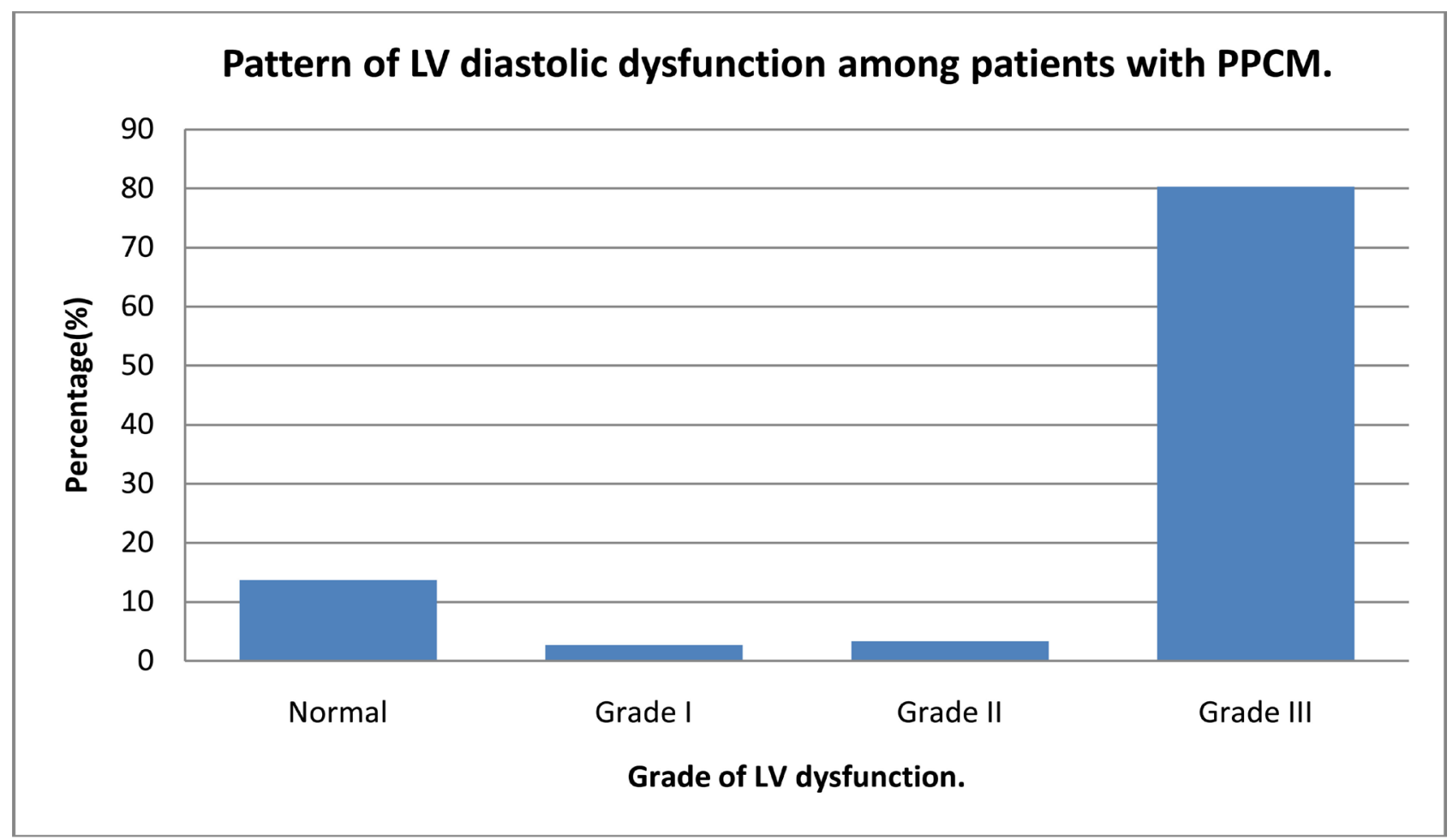

Key: LV, left ventricular; PPCM, peripartum cardiomyopathy.

Figure 2. Pattern of LV dysfunction among patients with PPCM. 
Table 2. Echocardiographic characteristics of the patients with PPCM.

\begin{tabular}{ccc}
\hline Variable & Mean & Standard deviation \\
\hline LA (mm) & 46.4 & 7.0 \\
IVSd (mm) & 8.40 & 1.3 \\
LVIDd (mm) & 59.4 & 7.8 \\
LVIDs (mm) & 47.3 & 12.4 \\
LVPWTd (mm) & 8.8 & 1.3 \\
EF (\%) & 30.5 & 8.1 \\
Mean DT (ms) & 181 & 56 \\
Mean RVSP & 33.7 & 8.3 \\
\hline Left ventricular thrombus & Frequency (n) & Percentage (\%) \\
LV diastolic dysfunction & 10 & 86.5 \\
Pulmonary hypertension & 157 & 76.8 \\
\hline
\end{tabular}

Key: LA, left atrium; IVSd, interventricular septum thickness at end-diastole; LVIDd, left ventricular end diastolic dimension; LVIDs, left ventricular end systolic dimension; LVPWd, left ventricular posterior wall thickness at end-diastole; EF, ejection fraction; LV, left ventricular; DT, deceleration time; RVSP, right ventricular systolic pressure.

\section{Discussion}

Peripartum cardiomyopathy was the commonest aetiology of heart failure among females, accounting for more than half of cases (62.5\%). This disorder has been recognized as an important cause of heart failure in Northern Nigeria particularly Zaria, Sokoto, Katsina and Kano, predominantly affecting the Hausa-Fulani ethnic tribes and rare among the Yorubas in Southern Nigeria [28] [29] [30] [31]. One hundred and eighty (99\%) of the patients are Hausa-Fulani while only $2(1 \%)$ are Yoruba. A previous study in Kano reported a lower prevalence of $31.4 \%$ among heart failure admitted patients [32]. The higher prevalence in this study may be explained by the availability of the echocardiographic service in the centre which has improved the rate of detection. A similar high prevalence of up to $60 \%$ was reported in Sokoto State, among heart failure admitted patients [29]. The prevalence is however lower in other parts of the world. In South Africa, it was reported to be 1:1000 live births, while in Haiti it was found to be 1:300 live births [33] [34].

In our study, patients with PPCM were found to be younger compared to other female patients $(27.8 \pm 12.3$ years vs. $42.4 \pm 11.3$ years, $\mathrm{p} \leq 0.001)$. This is in keeping with previous reports in Kano and Sokoto [30] [31] [32]. Patients from Zaria, South Africa and Haiti were however older than our patients with the mean age of the South African and Haiti patients being $31.6 \pm 6.6$ years and $31.8 \pm 8.1$ years respectively [33] [34]. This therefore explains the relatively larger number of primipara in our study. Twin pregnancy was reported in 18 (9.8\%), all of whom are multi and grandpara, similar to previous reported by Isezuo et 
al., in Sokoto [30].

In this study the incidence of traditional Puerperal practice is lower than in previous reports [30] [35] [36]. Hot water bath was practiced in 84 (46.2\%) while $67(37 \%)$ consumed dried lake salt pap (kunun kanwa). These practices have been previously described in over $90 \%$ of Hausa-Fulani tribes of Nigeria [35] [36]. These practices are believed to stimulate breast milk production and general health of the mother. The resultant volume overload is thought to aggravate heart failure in a heart already stressed by the haemodynamic changes of pregnancy [36]. The decline in these practices may be attributed to the greater awareness of their hazardous effects and also its economic consequences since a lot of money is spent on buying fire wood for boiling the water. Despite this, however, the incidence of peripartum cardiomyopathy remains high, due to multifactorial etiology.

The prevalence of hypertension in current study is consistent with recent reports by Isezuo et al. and karaye et al. but lower than in older reports [28] [30] [31] [36]. Although the pathogenesis of hypertension in PPCM has not been well described, acute salt loading has been shown to cause hypertension in animals, with conflicting results in humans [36] [37]. Acute salt loading led to elevated blood pressure among the Zimbabweans but not Nigerians [38] [39].

Although more than half of the patients 124 (68\%) had severe LV systolic dysfunction, only 10 (5.4\%) had LV thrombus. Isezuo et al., in Sokoto reported LV thrombus in $12.3 \%$ of their study population [40]. We also reported a lower rate of cardioembolic stroke of $33.3 \%$ among our study population than in previous reports. This may be attributed to earlier detection with the availability of cheaper echocardiographic center, and early institution of appropriate medications including antiplatelet agents. Majority of the patients (86.5\%), with PPCM had LV diastolic dysfunction, of which severe (grade III) was the commonest form, a finding in keeping with previous reports [30] [41]. Some previous studies had also reported reversal of diastolic function with improved LV systolic function [33] [34] [41].

\section{Conclusions}

Peripartum cardiomyopathy is the leading cause of heart failure among women presenting for echocardiography in Murtala Muhammad Specialist Hospital, Kano, and North-western Nigeria. The incidence of the disease is rising despite some decline in the harmful traditional birth practices in the environment, thus reinforcing the importance of other aetiological factors.

This study has some limitations. The data collection was time-consuming as record keeping is done manually. There were also missing and incomplete data. As we aim to determine the prevalence of the disease, our patients were not followed up, thus outcome data in terms of mortality and recovery of left ventricular function were not available. However, this condition found to be the most common cause of heart failure among women in this tertiary health institution, 
forms basis for larger multicenter longitudinal study to understand the disease and reasons for the rising incidence.

\section{Recommendation}

We recommend continuous health education programmes to women of child bearing age on the risk factors of the disease and the importance of antenatal and postnatal period care. We also recommend focused echocardiographic screening of high risk women in the peripartum period to identify and treat asymptomatic left ventricular dysfunction. There is also the need to promote family planning measures to assist women who wish to avoid the higher risk of the disease and or relapse.

\section{References}

[1] Toure, I.A., Salissou, O. and Chapko, M.K. (1992) Hospitalizations in Niger for Complications from Arterial Hypertension. American Journal of Hypertension, 5, 322-324. https://doi.org/10.1093/ajh/5.5.322

[2] Oyoo, G.O. and Ogola, E.N. (1999) Clinical and Sociodemographic Aspects of Congestive Heart Failure Patients in Kenyatta National Hospital. Nairobi. East African Medical Journal, 76, 23-27.

[3] Bardgett, H.P., Dixon, M. and Beeching, N.J. (2006) Increase in Hospital Mortality from Non-Communicable Disease and HIV Related Conditions in Bulawaye Zimbabwe, between 1992 to 2000. Tropical Doctor, 36, 129-131. https://doi.org/10.1258/004947506777978217

[4] Kingue, S., Dzudie, A., Menanga, A., Akono, M. and Ouankou, M. (2005) A New Look at Adult Chronic Heart Failure in the Age of the Doppler Echocardiography: Experience of the Medicine Department at Yaoundé General Hospital. Annales de Cardiologie et D'Angeiologie, 54, 276-283.

https://doi.org/10.1016/j.ancard.2005.04.014

[5] Khatibzadeh, S., Farzadfar, F., Oliver, J. and Moran, E.M. (2013) Worldwide Risk Factors for Heart Failure: A Systematic Review and Pooled Analysis. International Journal of Cardiology, 168, 1186-1194. https://doi.org/10.1016/j.ijcard.2012.11.065

[6] Schocken, D.D., Benjamin, E.J., Fonarow, G.C., Krumholz, H.M. and Levy, D. (2008) Prevention of Heart Failure: A Scientific Statement from the American Councils on Epidemiology and Prevention, Clinical Cardiology, Cardiovascular Nursing and High Blood Pressure Research; Quality of Care and Outcomes of Research Interdisplinary Working Group; and Functional Genomics and Translational Biology. Circulation, 117, 2544-2565. https://doi.org/10.1161/CIRCULATIONAHA.107.188965

[7] Damasceno, A., Cotter, G., Dzudie, A., Silwa, K. and Mayosi, B.M. (2007) Heart Failure in Sub-Saharan Africa: Time for Action. Journal of the American College of Cardiology, 50, 688-693. https://doi.org/10.1016/j.jacc.2007.07.030

[8] Owosu, I.K. (2007) Causes of Heart Failure as Seen in Kumasi, Ghana. The Int J Third World Med, 5, 1-10.

[9] Mendez, G.F. and Cowie, M.R. (2001) The Epidemiological Features of Heart Failure in Developing Countries: A Review of the Literature. International Journal of Cardiology, 80, 213-219. https://doi.org/10.1016/S0167-5273(01)00497-1

[10] Yamani, M. and Massie, B.M. (1993) Congestive Heart Failure: Insights from Epi- 
demiology, Implications for Treatment. Mayo Clinic Proceedings, 68, 1214-1218. https://doi.org/10.1016/S0025-6196(12)60078-0

[11] Pearson, G.D., Veille, J.C. and Rahimtoola, S. (2000) Peripartum Cardiomyopathy: National Heart, Lung and Blood Institute and Office of Rare Diseases (National Institute of Health) Workshop Recommendations and Review. JAMA, 283, 1183-1188. https://doi.org/10.1001/jama.283.9.1183

[12] Ansari, A.A., Fett, J.D., Damascenu, A., Mayne, A.E., Onlamoon, M. and Sandstorm, J.B. (2002) Autoimmune Mechanisms as the Basis for Peripartum Cardiomyopathy. Clinical Reviews in Allergy \& Immunology, 23, 289-312. https://doi.org/10.1385/CRIAI:23:3:301

[13] Wash, J.J. and Burch, G.E. (1961) Post Partal Heart Disease. Archives of Internal Medicine, 108, 817-822. https://doi.org/10.1001/archinte.1961.03620120001001

[14] Hafkesbring, H.E. (1971) Toxic Postpartal Heart Disease. New Orleans Medical-Surgical, 44, 964-968.

[15] Demakis, J.G. and Rahimtoola, S.H. (1971) Peripartum Cardiomyopathy. Circulation, 44, 964-968. https://doi.org/10.1161/01.CIR.44.5.964

[16] The Task Force for the Diagnosis and Treatment of Chronic Heart Failure of the European Society of Cardiology (2005) Guidelines for the Treatment and Diagnosis of Chronic Heart Failure: An Executive Summary. European Heart Journal, 26, 1115-1140. https://doi.org/10.1093/eurheartj/ehi204

[17] Disease of Heart Blood Vessels (1964) Nomenclature and Criteria for Diagnosis. 6th Edition, Little, Brown, Boston, 114.

[18] Sahn, D.J., De Maria, A., Kisslo, J. and Weyman, A. (1978) Recommendations Regarding Quantitation in the M-Mode Echocardiography. Results of the Survey of Echocardiographic Measurements. Circulation, 58, 1072-1083.

https://doi.org/10.1161/01.CIR.58.6.1072

[19] Sahn, D.J., De Maria, A., Kisslo, J. and Weyman, A. (1978) The Committee on M-Mode Standardization of the American Society of Echocardiography: Recommendation Regarding Quantitation in M-Mode Echocardiography: Results of a Survey of Echocardiographic Measurements. Circulation, 58, 1072-1081. https://doi.org/10.1161/01.CIR.58.6.1072

[20] Teichholz, L.E., Kreulen, T. and Herman, M.V. (1976) Problems in Echocardiographic Volume Determinations: Echocardiographic-Angiographic Correlations in the Presence or Absence of Synergy. American Journal of Cardiology, 37, 7-11. https://doi.org/10.1016/0002-9149(76)90491-4

[21] Oh, J.K., Seward, J.B. and Tafik, A.J. (2006) Goal Directed and Comprehensive Examination. In the Echo Manual 3rd Edition, 390-400.

[22] Sliwa, K., Hilfiker-Kleino, D., Petrie, M.C., et al. (2010) Current State of Knowledge on Etiology, Diagnosis, Management and Therapy of Peripartum Cardiomyopathy: A Position Statement from the Heart Failure Associations of the European Society of Cardiology Working Group on Peripartum Cardiomyopathy. European Journal of Heart Failure, 8, 767-778. https://doi.org/10.1093/eurjhf/hfq120

[23] Ganau, A., Devereux, R.B., Roman, M.J., de Simone, G., Pickering, T.G., Saba, P.S., Vargiu, P., Simongini, J. and Laragh, J.H. (1992) Pattern of Left Ventricular Hypertrophy and Geometry in Essential Hypertension. American Journal of Cardiology, 19, 1550-1558. https://doi.org/10.1016/0735-1097(92)90617-V

[24] Remenyi, N., Wilson, A., Steer, A., et al. (2012) World Heart Federation Criteria for Echocardiographic Diagnosis of Rheumatic Heart Disease-An Evidence Based Guidelines. Nature Reviews Cardiology, 9, 297-309. 
https://doi.org/10.1038/nrcardio.2012.7

[25] WHO Expert Committee (1984) Cardiomyopathies. World Health Organization Technical Report Series, 697, 7-64.

[26] Jaffe, C.C. and Weltin, G. (1992) Echocardiography of the Right Side of the Heart. Cardiology Clinics, 10, 41-57.

[27] Armstrong, W.F. and Ryan, T. (2010) Echocardiography and Coronary Heart Disease. In: Feigenbarun's Echocardiography, Lippincott Williams and Williams, Philadelphia, 7th Edition, 427-472.

[28] Karaye, K.M., Sani, M.U., Mijinyawa, M.S. and Borodo, M.M. (2007) Aetiology and Echocardiographic Features of Heart Failure with Preserved and Reduced Ejection Fraction in Kano, Nigeria. Nigerian Journal of Basic and Clinical Sciences, 4, 11-17.

[29] Antony, K.K. (1980) Pattern of Cardiac Failure in Northern Savannah, Nigeria. Tropical and Geographical Medicine, 32, 118-125.

[30] Isezuo, S.A. and Abubakar, S.A. (2007) Epidemiologic Profile of Postpartum Cardiomyopathy in a Tertiary Care Hospital. Ethnicity \& Disease, 17, 228-233.

[31] Brokington, I.F. (1970) Peripartum Heart Failure. American Journal of Cardiology, 7, 63-68.

[32] Karaye, K.M. and Sani, M.U. (2008) Factors Associated with Poor Prognosis among Patients Admitted with Heart Failure in a Nigerian Tertiary Medical Center: A Cross-Sectional Study. BMC Cardiovascular Disorders, 6, 16. https://doi.org/10.1186/1471-2261-8-16

[33] Silwa, K., Forster, O., Libherber, E., Fett, J.D., Sundstrom, J.B., Hilfiker-Kleiner, D. and Ansari, A.A. (2006) Peripartum Cardiomyopathy: Inflammatory Markers as Predictors of Outcome in 100 Prospectively Studied Patients. European Heart Journal, 27, 441-446. https://doi.org/10.1093/eurheartj/ehi481

[34] Fett, J.D., Chritie, L.G., Carraway, R.D. and Murphy, J.G. (2005) Five Year Prospective Study of the Incidence and Prognosis of Peripartum Cardiomyopathy at a Single Institution. Mayo Clinic Proceedings, 80, 1602-1606. https://doi.org/10.4065/80.12.1602

[35] Davidson, N.M. and Parry, E.H.O. (1978) Peripartum Cardiac Failure. QJM, 188, 431-463.

[36] Davidson, N.M., Trevit, L.S. and Parry, E.H.O. (1974) Perpartum Cardiac Failure: An Explanation for Observed Geographic Distribution in Nigeria. Bulletin of the World Health Organization, 51, 203-208.

[37] Mundy, M.I. (1995) The Effects of Increased Salt Intake on Blood Pressure of Chimpanzes. Nature Medicine, 1, 1009-1016. https://doi.org/10.1038/nm1095-1009

[38] Mufunda, J., Chemistry, J.E. and Matenga, J. (1992) Blood Pressure Response to Acute Changes in Dietary Sodium in Young Zimbabweans. Journal of Hypertension, 10, 279-285. https://doi.org/10.1097/00004872-199203000-00012

[39] Safola, O.A., Arinze, E.C. and Mabayoje, M.O. (1998) The Cardiovascular and Serum Electrolytes Responses to Acute High Salt Loading in Normotensive Nigerians. The Nigerian Medical Practitioner, 35, 10-12.

[40] Isezuo, S.A. (2006) Echocardiographic Profile of Peripartum Cardiomyopathy in a Tertiary Care Hospital in Sokoto, Nigeria. Indian Heart Journal, 58, 234-238.

[41] Karaye, K.M., Lindmark, K. and Henein, M.Y. (2016) One Year Survivalin Nigerians with Peripartum Cardiomyopathy. Heart Views, 17, 55-61.

https://doi.org/10.4103/1995-705X.185114 